\title{
A dual process account of creative thinking
}

Andrew P. Allen* and Kevin E. Thomas**

*Correspondence Author

Centre for Occupational and Health Psychology

63 Park Place

School of Psychology

Cardiff University

CF10 3AT

UK

** School of Design, Engineering and Computing

Bournemouth University

Running Head: DUAL PROCESS CREATIVE PROBLEM-SOLVING

Submission Date: $25^{\text {th }}$ November 2009

Re-submission date: $7^{\text {th }}$ December 2010

Keywords: Creativity, dual processes, analytical thought, implicit reasoning 


\begin{abstract}
This paper explicates the potential role played by type 1 thinking (automatic, fast) and type 2 thinking (effortful, logical) in creative thinking. The relevance of Evans (2007) models of conflict of dual processes in thinking is discussed with regards to creative thinking. The role played by type 1 thinking and type 2 thinking during the different stages of creativity (problem finding and conceptualisation, incubation, illumination, verification and dissemination) is discussed. It is proposed that although both types of thinking are active in creativity, the extent to which they are active and the nature of their contribution to creativity will vary between stages of the creative process. Directions for future research to test this proposal are outlined; differing methodologies and the investigation of different stages of creative thinking are discussed.
\end{abstract}


Creativity is usually defined as the production of an idea, act or object that is both original and valued (Csikszentmihalyi, 1999). For centuries, there have been accounts of creative thinking as subconscious or intuitive and contrasting accounts of creative thought as purposeful and deliberative. An archetypal example of the former method is the structure of benzene appearing to Kekulé in a dream; an archetypal example of the latter method is Michelangelo's painstaking work on his decoration of the Sistine Chapel. However, there has been a lack of an explicit review of what role type 1 thinking (intuitive and fast) and type 2 thinking (logical and deliberative) play in creative thinking. It is our contention that both types of thought must be involved in creative thinking in order for creative solutions to be both imaginative and useful.

As well as defending the role of both forms of thinking in creativity, this paper has three aims: explicate which aspects or stages of creative thinking are more likely to rely on type 1 thinking and which are more likely to use type 2 thinking; outline how the two types of thinking interact in creative thinking, and provide directions for future research.

\section{DUAL PROCESS ACCOUNTS OF THINKING}

A classic argument in psychology has been between those who believe thought is associative and parallel and those who believe that it is symbolic and sequential (Sloman, 1996). One solution to this argument is to suggest that there are two kinds of thinking. To address findings that suggest people are prone to poor logical reasoning (e.g. Evans, Barston, \& Pollard, 1983) and violations of probability theory (e.g. Tversky \& Kahneman, 1983), Evans and Over (1996) distinguished between rationality1 and rationality2. Rationality1 involves thinking or behaving in a manner which should help to achieve one's goals, whereas rationality2 involves thinking or 
behaving according to normative rules (e.g. logic). Evans and Over suggested that, while many experiments had found people to be irrational according to the characteristics of rationality2, failure to complete experimental tasks correctly could often be attributed to participants relying upon rationality1 processes.

Similarly, Sloman (2002) proposed that type 1 thinking is based on personal knowledge and computations based on similarity, while ruled-based computation drives type 2 thinking, which is based on language and/or other formal systems. However, Evans (2008) pointed out that descriptions of type 1 thinking that focus on its associative properties may not be compatible with those that describe it as heuristic, implying that not all treatments of dual processing accounts of thinking conceptualise type 1 thinking in the same way. It has also been argued that some type 2 processes can be heuristic (e.g. Carruthers, 2009). For the purpose of our position we will use a broad definition of type 1 processes that includes fast, implicit and associative processes.

Evans (2009) has suggested the use of the terms "type 1 processes" and "type 2 processes"; he has pointed out that Sloman's (1996) use of the term "systems" suggests very specific components of the mind, while Evans and Over's (1996) "systems" are defined at a much more general level. The use of the term "system" also implies that there is some cognitive architecture responsible for the different types of thinking (Evans, 2009). To avoid ambiguity, and because the assertion of a cognitive architecture is unimportant to our arguments, we will refer to type 1 and 2 processes.

Stanovich (2009) has suggested that that type 2 thinking can itself be understood as comprising the reflective and the algorithmic mind. The algorithmic mind can override type 1 thinking to implement analytical thinking, while the reflective mind is 
responsible for higher goal states and thinking dispositions. Although it would be interesting to understand how different individuals' goals and dispositions drive creative thinking, the focus of this paper is the algorithmic mind, as it is concerned with how and when type 2 thinking may override type 1 thinking.

Evans (2007) has described three models of the conflict between automatic (type 1) and analytical (type 2) thinking. In the pre-emptive conflict resolution model, the use of type 1 or type 2 is chosen at the beginning. It has been asserted that people can choose a more cautious and critical or a more "freewheeling" approach to creative thinking (e.g. Nickerson, 1999). Klaczynski (2000) proposed a pre-emptive conflict resolution model in describing adolescent thought, arguing that choice of either faster or more analytical thinking is driven by personal theories (e.g. of social behaviour) held by the individual.

It is questionable if the pre-emptive conflict-resolution model could be applied to pressurised conditions, where type 1 might be relied upon without any prior deliberation. There is also a lack of specification of how type 1 or 2 thinking is chosen. For example, in Klaczynski's (2000) description of such a model, a preconscious (type 1) check occurs to see if information is theory-congruent. Type 1 or type 2 thinking is then chosen on the basis of this check, thus implying that type 1 thinking comes first.

In the parallel-competitive model, both types of thinking operate in parallel to produce a response, which sometimes leads to conflict. The idea of type 2 thinking operating in parallel with type 1 thinking seems somewhat contradictory to its sequential and deliberative nature. However, type 1 thinking may continue after it has proposed its first response, by responding to the outcome of type 2 thinking. Sloman (2002) has pointed out that certain thinking tasks can cause people to believe two 
contradictory ideas (one based on type 1 thinking and one based on type 2 thinking) at the same time. When people contrast these conflicting ideas, they could be described as engaging in a form of dialectical thinking (discussed below).

Finally, the default-interventionist model posits that type 1 thinking cues automatic responses that may be altered by type 2 thinking. This model has been supported by Stanovich (1999). In the context of a brief experiment it may be difficult to distinguish between a case where type 1 thinking comes first and a case where both types of thinking work together for a short period of time, before type 1 thinking finishes and type 2 thinking continues its slower processing (E.R. Smith \& DeCoster, 2000). However, in terms of long-term creative work the default-interventionist model fits nicely with the idea that type 1 thinking drives problem finding and insight, while type 2 thinking works on the elaboration and refining of a creative idea or solution.

There seems to be little or no consensus over which model of dual process thinking is generally preferable. Evans (2007) has suggested that different models may be useful for different cognitive processes. Given the complexity of creativity, it may be the case that different models of dual process thinking are more or less useful during different stages of creative thinking.

\section{DUAL PROCESS THINKING DURING THE STAGES OF CREATIVE}

\section{THINKING}

To look more closely at how type 1 and type 2 thinking are involved in creative thinking, it is useful to consider the different stages involved in creative thinking. There are clear qualitative differences between the stages discussed below, and it is 
posited here that different types of thinking will be more active during some stages than others.

Various ways of dividing the creative process into stages or steps have been suggested. However, Ochse (1990), pointed out that most classic conceptions of creativity include similar stages. The stages we deal with are problem finding and conceptualisation, incubation, illumination, verification and dissemination.

\section{Problem Finding and Conceptualisation}

Creativity usually begins with the identification (or construction) of a problem. "Auditing" of how things work at present using type 2 thinking may help to draw attention to what problems exist. For example, critically acclaimed professionals in the arts and sciences spent a greater period of time finding a problem on a decontextualised task than competent peers (Rostan, 1994). Once the problem has been identified, one needs to elaborate on its nature in order to get a sense of what a useful and novel solution might look like.

Research with gifted children by Gallucci, Middleton and Kline (2000) has found a positive relationship between a measure of concern over mistakes and personal standards and a subscale (Something About Myself) of the Khatena-Torrance Creative Perception Inventory (KTCPI) (Khatena \& Torrance, 1976). The KTCPI is a biographical, self-report measure, so it would be interesting to investigate the relationship between perfectionism and tests of creative performance. Perfectionists should be more likely to systematically evaluate a current state of affairs, and so rely on type 2 thinking to a greater extent when problem finding.

Perhaps the most explicit empirical contrast between type 1 thinking and type 2 thinking in relation to problem conceptualisation comes from a study by Ruscio and 
Amabile (1999). They asked participants to solve a problem after watching one of two instructional videos: one gave step-by-step algorithmic instructions (to prime type 2 thinking) while the other ("heuristic") video gave the same instructions, but had them loosely grouped by functional similarity instead of in the order in which they were to be performed (to prime type 1 thinking). Ruscio and Amabile found no difference between groups in terms of task completion or instructional information retained. However, judges who blind-rated the creativity of products and the closeness of the products to those depicted in the video rated the algorithmic group as more creative when they followed the video instructions more closely and rated products of the heuristic group more highly the more they deviated from the video instructions.

The design of Ruscio and Amabile's study is somewhat artificial, as the conceptualisation of the problem was given to the participants. Nonetheless, it suggests that both types of thinking are useful, and that later stages of creative thinking should use the same type of thinking that was relied upon for defining the nature of the problem.

Dialectical or Janusian thinking may be useful in facilitating creativity (Benack, Basseches, \& Swan, 1989; Rothenberg, 1990). Dialectical thinking has been described as the simultaneous consideration of two opposite poles of the same idea that are brought together to form a synthetic idea (Guignard \& Lubart, 2006). The contention that dialectical thinking aids creativity has been supported by research by $\mathrm{Wu}$ and Chiou (2008), who found a positive correlation between dialectical thinking and performance on a divergent thinking task in young Taiwanese adults. However, Paletz and Peng (2009) found that Asians and Asian-Americans received similar originality scores on a test of problem conceptualisation regardless of their tendency towards 
dialectical thinking, whereas Caucasians displayed a negative relationship between dialectical thinking and originality, which suggests that the relationship between dialectical thinking and creativity may be culture-specific. Wu and Chiou's (2008) research measured dispositional dialectical thinking; a more experimental approach could be useful.

Although dialectical thinking can be done in a serial, methodical way, it may be possible that it occurs at a sub-conscious level. Rothenberg (1990) found that artists and scientists that he interviewed were often initially unaware of the role of dialectical thinking in their work, but upon further interviewing agreed that their work had been inspired by contrasting polar opposites. This would suggest that dialectical thinking occurred through type 1 thinking. It may, however, be possible that these ideas about dialectical thinking were implanted through the interview process, or that it is simply easy to re-interpret creative ideas as arising from the contrast of opposing ideas. Further research could also investigate in vivo the use of dialectical thinking in creative thinking. For example, notebooks could be searched for examples of dialectical thinking to see if such thinking is explicitly expressed during problem conceptualisation.

In contrast to an account prioritising type 1 thinking, it seems plausible that the kind of problems described by Sloman (2002), where one believes two contradictory ideas at once, each one coming from a different type of thinking, are useful in facilitating dialectical thinking. One is aware of the contradiction while at the same time appreciating both of the competing ideas. This suggests that the parallel-competitive model (Evans, 2007) of dual processes, where both types of thinking operate simultaneously, is applicable to dialectical problem conceptualisation. 
Markman, Lindberg, Kray and Galinsky (2007) found that a counterfactual mindset can improve performance on creativity and problem-solving tasks. A counterfactual mindset is a cognitive orientation where alternative versions of reality are likely to be considered. Specifically, Markman et al. found that additive counterfactual thinking (i.e. adding antecedent events to reconstruct reality) improved performance in generating novel uses for a brick (a task similar to Alternate Uses; Christensen, Guilford, Merrifield, \& Wilson, 1960) and also on a Scattergories task which involved thinking of words that fit into a particular category (e.g. famous actors) and begin with a given letter. In contrast, Markman et al. (2007) found that subtractive counterfactual thinking (i.e. subtracting antecedent events to reconstruct reality) improved performance on tasks which required less divergent thinking: a version of the Remote Associations Task (RAT; Mednick, 1962) and syllogisms,.

Research by Goldinger, Kleider, Azuma and Bleike (2003) seems to indicate that counterfactual thoughts arise automatically, and active thought is required to suppress them, consistent with the default-interventionist model (Evans, 2007). Participants were required to make mock-jury decisions based on incidents that were altered in minor ways so that they either did or did not inspire counterfactual thinking. They also had to memorise irrelevant information while making their decisions. Goldinger et al. found that participants with poor word span awarded less compensation to the victim in the counterfactual scenarios, suggesting that they did not have the type 2 thinking resources to override the automatic counterfactual thoughts. The use of control groups ruled out the possibility that poorer word span is simply correlated with a different style of moral reasoning. However, the counterfactual-priming scenarios that Goldinger et al. used involved descriptions of unusual decisions that would prime subtractive counterfactual thought, so it may still be questionable if 
additive counterfactual thought arises automatically. It has also been hypothesised that counterfactual thinking is characteristic of dreams (McNamara, 2000), and this may help people to simulate alternative ways of dealing with difficult situations (McNamara, Andresen, Arrowood, \& Messer, 2002).

Feldhusen (2006) has emphasised the role of prior knowledge in understanding a creative task by suggesting that clarification of the problem occurs through relating the problem to similar tasks in one's knowledge base. Research has not found robust evidence for the hypothesis that the flexibility of divergent thinking is related to the breadth of one's knowledge base (Scott, 1997). It may be the case that while having a large number of examples of problems in one's memory can help to understand the problem, it may lead to a solution based on synthesis or the application of a predictable solution, rather than more radical novelty. Experts tend to have a greater amount of automaticity in their thinking, and so are less dependent on working memory and serial processing (VanLehn, 1989). This would seem to suggest that the degree to which type 2 thinking is necessary will depend upon the level of one's knowledge in the area where a creative solution is required. For example, an experienced film director should be able to decide on how to film a scene with less step-by-step, analytical thinking than a novice.

Although Sternberg (2006) argued that experts should typically approach tasks in a more systematic way, this argument could be accommodated by suggesting that while behaviourally more systematic, the performance of experts is not necessarily step-bystep at a cognitive level; a systematic method has become automatic for them. Notwithstanding the problems outlined above with the pre-emptive conflict resolution 
model (Evans, 2007), experts may simply be better at choosing type 1 or type 2 thinking when approaching a task.

\section{Incubation}

A typical account of the incubation stage of creative thinking is that one stops thinking of a problem for a while, and a new insight is available when one returns to the problem (Stokes, 2007). It is typically hypothesised that the unconscious mind works on the task at hand during incubation (S.M. Smith \& Dodds, 1999). Ellwood, Pallier, Snyder and Gallate (2009) found that, when generating ideas, performance was strongest when participants worked on an unrelated task during a break, rather than working on a similar task during the break or having no break at all. This would seem to support the idea that leaving a problem aside for a while can facilitate creative thinking. Similarly, three experiments by Dijksterhuis and Meurs (2006) indicated that people who did an unrelated distractor task came up with more divergent ideas than those who were given time to think consciously about the question or had to answer immediately, although the authors' definition of divergent thinking was rather arbitrary in Experiment 1 (coming up with names for new pastas that didn't end in "i"; this ignored other potential factors that could indicate divergent thinking, such as if the proposed new names did not sound like existing pasta names in other ways,).

S.M. Smith and Dodds (1999) identified a number of different theories to explain incubation effects, not all of which suggest unconscious processes. Theories include recovery from fatigue, forgetting inappropriate mental sets and opportunistic assimilation (assimilating chance environmental events into one's thoughts by being alert to potentially useful clues or analogies). The latter explanation was supported by 
Simonton (1995), who suggested that the idea of opportunistic assimilation is supported by the innovation of thinkers with numerous professional contacts and varied projects.

Research that has involved participants working on another task during a break from the main task (e.g. Penney, Godsell, Scott, \& Balsom, 2004) has not tended to support the idea that incubation is simply due to recovery from fatigue. Research by Sio and Rudowicz (2007) showed no evidence for the idea that inappropriate mental sets are forgotten, but instead supported the spreading activation hypothesis (S.M. Smith, 1995), which suggests that activation spreads to the relevant nodes during incubation. If so, this would suggest that associative, implicit processes are actively at work during the incubation period.

Segal (2004) challenged the idea that the unconscious mind is at work on a task during incubation, and argued that incubation simply allows one to organise the problem in a new way. This was supported by research indicating that the length of a break, which began once the participant had reached an impasse, did not affect insight problem-solving (Segal, 2004). Insight problems are those that require some kind of new or unfamiliar response, involving a change in one's view of the problem, in order to find the solution (Dominowski, 1995). However, Segal's findings could be interpreted as an indication that type 1 thinking works quite quickly during incubation, and that the short break was long enough for type 1 thinking processes to work out the solution.

A meta-analytic review by Sio and Ormerod (2009) analysed a number of potential mediators that could potentially explain the inconsistent findings from the incubation literature on whether or not unconscious processes account for incubation. Sio and Ormerod found that the use of low demand tasks during the incubation period was 
beneficial; the authors acknowledge that this could mean that high demand tasks are less beneficial as they do not allow covert conscious thought about the main problem during the incubation period. This would in turn undermine some of the evidence that unconscious processes underlie incubation, as it suggests that participants are actually still reasoning about creativity tasks while doing irrelevant distracter tasks.

Whether or not the unconscious mind is active during incubation, it seems unlikely that type 2 thinking is involved. Indeed, the greater the type 2 thinking resources one has at one's disposal, the less likely one is to go through incubation, as one will be more likely to find a creative solution through serial processing. Davidson (1995) found that participants with a lower I.Q. benefited more from the provision of cues when solving insight problems, which suggests that these participants may have reached the impasse that leads to the stage of incubation. Although it was also observed that individuals with a higher I.Q. were more likely to make sudden realisations, Davidson did not suggest that this was due to less intelligent participants solving the problems in a more step-by-step manner. Instead, it seems plausible that less intelligent individuals were more likely to overestimate their closeness to reaching a solution, meaning that the more intelligent participants were more aware of the suddenness of insights when they occurred.

\section{Illumination}

Inspiration or illumination would seem to be reliant upon type 1 thinking, which is described as intuitive and associational. Weisberg (2006) has pointed out that insight (i.e. where the solution becomes suddenly obvious following a period of frustrated effort) is typically seen as defying logic in problem-solving, as it does not follow from 
the individual's prior thoughts. An interesting piece of research by Schooler, Ohlsson and Brooks (1993) seems to support this. They found that participants who, during an interruption in insight problem-solving, verbalised their thinking strategies performed worse than controls who engaged in an unrelated activity during the interruption.

However, Sawyer (2006) has highlighted the effort that goes into most creative works. Sawyer has used the example of the work of professional authors (and their editors) to emphasise the importance of the process of perfecting a creative work, and suggested that the "visionary" image of the creator, and thus the emphasis on type 1 thinking, is culturally and historically specific.

Ball and Stephens (2009), in studying the completion of insight problems, employed a methodology that contrasts thinking aloud with articulatory suppression (AS), a condition where an irrelevant word or phrase (in this case, repeating a number sequence) is repeatedly articulated. The idea was that AS would use up working memory resources, so that if insight requires these resources (which would suggest that it is a type 2 thinking-driven process) then insight problem-solving will be impaired by AS. If insight does not require working memory resources (in other words, if it is implicit or type 1 thinking-driven) then AS should not have an effect. Ball and Stephens found that AS impaired insight problem-solving relative to a control group for easy tasks and relative to both the control group and the thinking aloud group for more difficult tasks. This suggests that type 2 thinking is required.

Finke (1995) drew a distinction between divergent insight and convergent insight, based on divergent and convergent thinking (Guilford, 1956; Mednick, 1962). Insight problems (i.e. those that are likely to involve sudden insight) tend to involve convergent insight, where a structure is found that makes sense of ostensibly unrelated elements. Divergent insight, on the other hand, occurs when one finds novel 
uses or implications for an existing structure, and is probably more common in various forms of art. Much of the research on insight uses insight problems rather than more open-ended tasks that would require divergent insight, and so has arguably only investigated one kind of insight.

Boden (1994) posited that dimensions of a conceptual space within a domain are defined by the domain's principles, which define a set of possibilities. Progress in creativity stems from explorations of the conceptual space (or mental representations thereof) that lead to changes in the dimensions of conceptual space. A clear example would be in music, where $19^{\text {th }}$ and $20^{\text {th }}$ century composers increased the number of modulations that were possible in compositions (Boden, 1994). Type 2 thinking could be useful in outlining the parameters of a creative domain, and deciding how to extend them.

A similar account, also based on mental representations, has been posited by Byrne (2005). Problems that typically involve a moment of insight just before one solves them are often represented in a limited way. For example, when completing the ninedot problem, one may represent the four lines as staying within the square formed by the dots. The moment of insight occurs when an aspect of the problem's mental representation that was previously unchangeable is altered. Byrne argued that reasoning about what might have happened is a form of imagination, so perhaps inspiration can derive from type 2 thinking. Although the findings of Goldinger et al. (2003) seem to suggest that such thought can arise automatically, the application of these thoughts to a problem may involve deliberative reasoning. 
Gilhooly and Murphy (2005) investigated if problems that require insight were solved more easily by people who scored higher on tests of working memory and executive function, which the authors used as an indirect measure of type 2 thinking. Their results indicated that participants who scored higher on tests of figural fluency and alternative uses (described as measures of executive function) did significantly better on insight problems. However, there was no significant effect on insight problem-solving for performance on most of the tests of working memory. As the authors point out, as well as measuring executive function, figural fluency and alternative uses also measure cognitive flexibility, which may require the parallel processing of type 1 thinking, so it is difficult to say if their findings clarify if type 2 thinking plays a role in insight problem-solving. As insight problems (with the solutions known to the researchers) were used by Gilhooly and Murphy (2005), divergent insight (Finke, 1995) was not measured, and so their research may not be relevant to the kind of creativity discussed by authors such as Boden (1994).

\section{Verification}

Ideas are often expanded during verification, so there is still a role for type 1 thinking to play. The creative thinker may also be concerned with whether or not a creative product has "intuitive" appeal, and so may fall back on type 1 thinking. When critiquing a new strategy, one may imagine different ways in which the strategy might play out (Nickerson, 1999), and one may use associative thought for this purpose. When verifying a solution that has already begun to be implemented, counterfactual thinking may be useful. This may arise automatically, at least if it involves subtractive counterfactual thought (see discussion of Goldinger et al.'s [2003] study above), 
although it may need to be appraised by type 2 thinking, consistent with the defaultinterventionist hypothesis (Evans, 2007).

It is more obvious that verification should involve type 2 thinking. Type 2 thinking is described as deliberate, and in order for verification to happen the thinker must check through the creative "product" for flaws. One needs to evaluate the strengths and weaknesses of one's thoughts so that the best ideas can be chosen for further progress (Guignard \& Lubart, 2006). Reasoned evaluation is necessary to ensure that original ideas are useful, rather than just bizarre (Runco, 2006).

\section{Dissemination}

Following verification, thinkers are satisfied with the intrinsic quality of their creative solutions. However, they will usually want to make their work known to others. Simonton (e.g. 1988) has contended that creativity requires persuasion and social influence. In other words, a creative act can only be fully creative if it reaches an audience. Although social persuasion as a requirement or essential aspect of creativity has been challenged (e.g. Johnson-Laird, 1988; Nickerson, 1999), many tasks requiring creative thought (e.g. problems with national infrastructure) will not be successfully dealt with until the idea for the solution has been disseminated.

Associative thinking may be useful in thinking of novel ways to make others aware of one's creative ideas. During dissemination, the development of ideas may be influenced by the social reaction to one's work. Amabile (1996) described how the poet Anne Sexton worried that winning a grant cheapened her work, and how she warned a fellow writer not to let an award he had won lead to complacency. Step-bystep verification may take place when creative thinkers use others' responses to their 
work to evaluate its usefulness. A particularly strong example of the effect of social reaction on creativity is a "high-stakes performance" (Gardner, 1994), which involves carrying out actions in public in order to cause social or political change. The details of such performances have to be developed in response to the reactions of people or institutions that are targeted as an audience. Although some small insight presumably comes before the performance, dissemination is given temporal precedence in Gardner's outline of the high-stakes performance.

Although a role can be given to both types of thinking in dissemination, a more socially-orientated account may be needed to fully explain the success of a creative idea. Csikszentmihalyi (1988) proposed a dynamic model of the creative process in which the creative person interacts with the domain (the symbolic system of the culture in which the creative act is embedded) and the field (the group of people who affect the structure of the domain). This model could be used to give a more comprehensive account of why some creative solutions are more influential than others. For example, whether an idea is accepted by the relevant field as creative or not is often related to the values of the decision-makers within that field rather the intrinsic quality of the work (Runco, 2006). Nonetheless, thinkers with expertise in their domain should be able to fit their work to the tastes of the field, if they choose.

\section{INSERT TABLE 1 ABOUT HERE}

\section{Discussion}

This paper contends that both type 1 and type 2 thinking are active at all stages of creative thinking, with the possible exceptions of incubation (for which type 1 thinking may be responsible). Despite anecdotal evidence to the contrary (e.g. great 
ideas appearing, fully-formed, in dreams), it is unlikely that highly creative solutions can be carried out in full without type 2 thinking.

Policastro (1999) has suggested that the creative process begins with vague, impressionistic thoughts that gradually become more explicated. This is similar to the default interventionist model (Evans, 2007), with semi-conscious ideas from type 1 thinking being tested and refined by type 2 thinking. Runco (2006) has taken a less sequential view, arguing that creative thinking is a simultaneous, coherent process rather than a series of discrete stages. This makes intuitive sense; for example, conceptualisation can often be an arduous task, and "later" stages may be drawn upon in outlining the nature of the problem. Similarly, Brophy (1998) argued that a full process of creative thinking should involve alternating between convergent evaluation and divergent ideation. Such descriptions of the stages of creativity are probably more in line with the parallel competitive model (Evans, 2007), where both types of thinking operate simultaneously. Arguments like these do not contradict the existence of the stages discussed above; they simply challenge the idea that the creative thinker finishes one stage completely before progressing to the next.

A synthesis of the default interventionist model and the parallel competitive model, based on time frame of creative thinking, is possible. During work on a brief task or a small section of a longer task (these are more likely to be investigated using experimental methods), the default interventionist model applies, as a short period of associative thought is followed by a quick verification of one's idea using sequential processing. During work on long creative projects (the kind of problem that is more likely to be investigated using case study methods), the parallel competitive model applies, as one moves between the stages of creative thinking, alternating between type 1 and type 2 thinking. 


\section{DIRECTIONS FOR RESEARCH}

Although much of the research discussed here has only indirectly dealt with the issue of dual processes of thinking in creative thinking, it should be possible to employ various methodologies to empirically study this field.

Runco and Sakamoto (1999) argued that an experimental approach to creative thinking is useful because of the complexity of creativity; other variables can be controlled for. However, they acknowledge that control may come at the cost of the spontaneity of creative thought. This could be particularly problematic for the area of dual processes in creative thinking, as it suggests that the experimental situation could encourage participants to engage in more type 2 thinking than they would in the course of everyday thinking.

Stanovich and West (1998) found that people's performance on one task which induces a conflict between type 1 and 2 thinking (e.g. syllogisms where there is a conflict between the logically correct conclusion and a conclusion based on prior belief) will tend to be modestly but significantly correlated with performance on another such task, indicating that there are systematic individual differences in the tendency to use type 2 thinking. It could thus be possible to compare performance on creative tasks between those who are prone to type 2 thinking and people who are less so.

Participants are more likely to rely upon type 1 thinking when time constraints are used (e.g. Evans \& Curtis-Holmes, 2005). Although time constraints can be easily applied in the laboratory, external validity need not be totally sacrificed; time 
constraints often occur in the real world, perhaps particularly in organisational settings. Those working in the advertising world will be familiar with time constraints on creative thinking; they could potentially be a good target population.

Think-aloud protocols, while useful for developing a narrative account of a process (van Someren, Barnard, \& Sandberg, 1994), may exaggerate the role of type 2 thinking. This is because it may be the case, as Evans and Over (1996) have suggested, that the outcome of type 1 thinking is available to conscious thinking, but the workings of type 1 thinking are not. Given the serial nature of think-aloud protocols, they may not be able to identify parallel processes; eye tracking may be more useful (Evans, 2007). However, similar to the experimental findings of Stanovich \& West (1998), analysis of think-aloud protocols have suggested some possible individual differences in the use of type 1 and type 2 thinking; Khandwalla (1993) identified the cognitive styles "intuitive ideator" and "anxious analyst" from protocols of a divergent thinking task. In an experimental context, thinking aloud may be useful for identifying if type 2 thinking is being used when contrasted with articulatory suppression (Ball \& Stephens, 2009). Think-aloud protocols also have an advantage over more autobiographical measures in that they do not suffer from problems of trying to remember how one thought in the past.

Despite the problems with (auto)biographical methods, a case study approach may also prove useful; it could allow for increased external validity by looking at work on a project over an extended period of time (Gruber \& Wallace, 1999). This could be particularly useful in observing problem finding, where people may spend years "going through the motions" within their field before finding a truly important problem. Although this paper has mostly focused on the general process of creative 
thinking, the case study approach can be very useful in studying instances of exceptional creativity, which may employ the two types of thinking in different ways. For example, type 2 thinking may be used more extensively during exceptionally creative thought, as the evaluation of the verification stage may last for a longer period of time.

\section{Investigating specific stages of creative thinking}

If the objective of a task is fully and explicitly stated then research participants will not have to think of how the task itself could be improved. Thus, to investigate problem finding and conceptualisation, the use of ambiguous tasks is necessary. For example, Reiter-Palmon, Mumford, O’Connor Boes and Runco (1997) devised problems relating to everyday life for university students. One task describes a student who was having trouble deciding whether or not to pursue postgraduate studies. Participants are asked what they would do in this situation. Although this task may be useful for investigating how people conceptualise problems, it does not require them to find a problem, as the problem is already evident. A task for investigating problem finding would ideally present a scenario that is not evidently problematic (e.g. advertising an unusual product: one can advertise it using standard techniques, or one can find a problem that the product ameliorates). Asking participants to devise problem restatements can be used to measure overall quality as well as fluency and originality of problem construction but is somewhat artificial, as it encourages a focus on goals at the expense of restrictions or information needed (Reiter-Palmon \& Robinson, 2009).

The study of insight should ideally not rely solely on insight problems (i.e. those involving an "aha" moment). Insight problems have a tendency to present information 
so as to lead the problem solver into a limited conceptualisation of the problem that will make it almost impossible to solve (Segal, 2004). Creative acts in real life are not constructed in advance (although thinkers may themselves decide to follow an unfruitful approach), so sudden insight outside the lab (e.g. in the arts) should also be studied.

Research on verification should focus on solutions that participants themselves propose rather than a novel solution provided by the researcher. Ideas that participants have not come up with themselves may encourage different approaches to verification; participants may not have access to the process used to generate the researcher's idea or may be artificially uncritical in order to please the researcher. If it is the case that participants do not know how the idea was generated, they may be more inclined to use associative processes to imagine how the idea was generated rather than using more deliberatively critical processes to critique the processes through which the idea was generated.

\section{REFERENCES}

Amabile, T.M. (1996). Creativity in context. Boulder, CO: Westview Press.

Ball, L. J., \& Stevens, A. (2009). Evidence for a verbally-based analytic component to insight problem solving. In N. Taatgen \& H. van Rijn (Eds.), Proceedings of the Thirty-First Annual Conference of the Cognitive Science Society. Austin, Texas: Cognitive Science Society.

Benack, S., Basseches, M., \& Swan, T. (1989). Dialectical thinking and adult creativity. In E.P. Torrance, J.A. Glover, R.R. Ronning \& C.R. Reynolds (Eds.), Handbook of creativity (pp.199-208). New York: Plenum. 
Boden, M.A. (1994). What is creativity? In M.A. Boden (Ed.), Dimensions of creativity (pp.75-117). Cambridge, MA: MIT Press.

Brophy, D.R. (1998). Understanding, measuring and enhancing individual creative problem-solving efforts. Creativity Research Journal, 11(2), 123-150.

Byrne, R.M.J. (2005). The rational imagination. Cambridge, MA: MIT Press.

Carruthers, P. (2009). An architecture for dual reasoning. In J.St.B.T. Evans \& K. Frankish (Eds.), In two minds: Dual processes and beyond (p. 109-127). Oxford, UK: Oxford University Press.

Christensen, P. A., Guilford, J. P., Merrifield, P. R., \& Wilson, R. C. (1960). Alternate uses. Beverley Hills, CA: Sheridan Psychological Services

Csikszentmihalyi, M. (1988). Society, culture and person: A systems view of creativity. In R.J. Sternberg (Ed.), The nature of creativity (pp. 325-339). Cambridge, UK: Cambridge University Press.

Csikszentmihalyi, M. (1999). Creativity. In: R.A. Wilson \& F.C. Keil (Eds.), MIT encyclopedia of the cognitive sciences (pp. 205-206). Cambridge, MA: MIT Press.

Davidson, J.E. (1995). The suddenness of insight. In R.J. Sternberg \& J.E. Davidson (Eds.), The Nature of Insight (pp.125-155). Cambridge, MA: MIT Press.

Dijksterhuis, A., \& Meurs T. (2006). Where creativity resides: The generative power of unconscious thought. Consciousness and Cognition, 15, 135-146.

Dominowski, R.L. (1995). Productive problem-solving. In S.M. Smith, T.B. Ward \& R.A. Finke (Eds.), The creative cognition approach (pp. 73-95). Cambridge, MA: MIT Press.

Ellwood, S., Pallier, G., Snyder, A., \& Gallate. J. (2009). The incubation effect: Hatching a solution? Creativity Research Journal, 21(1), 6-14. 
Evans, J.St.B.T. (2007). On the resolution of conflict in dual process theories of reasoning. Thinking and Reasoning, 13(4), 321-339.

Evans, J.St.B.T. (2008). Dual-processing accounts of reasoning, judgment, and social cognition. Annual Review of Psychology, 59, 255-278.

Evans, J.St.B.T. (2009). How many dual-process theories do we need? One, two, or many? In J.St.B.T. Evans \& K. Frankish (Eds.), In two minds: Dual processes and beyond (p. 33-54). Oxford, UK: Oxford University Press.

Evans, J.St.B.T., Barston, J. L., \& Pollard, P. (1983). On the conflict between logic and belief in syllogistic reasoning. Memory \& Cognition, 11(3), 295-306.

Evans, J.St.B.T., \& Curtis-Holmes, J. (2005). Rapid responding increases belief bias: Evidence for the dual-process theory of reasoning. Thinking and Reasoning, 11(4), 382-389.

Evans, J.St.B.T., \& Over D.E. (1996). Rationality and reasoning. Sussex, UK: Psychology Press.

Feldhusen, J.F. (2006). The role of the knowledge base in creative thinking. In J.C. Kaufman \& J. Baer (Eds.) Creativity and reason in cognitive development (pp. 137144). Cambridge, UK: Cambridge University Press.

Finke, R.A. (1995). Creative insight and preinventive forms. In R.J. Sternberg \& J.E. Davidson (Eds.), The nature of insight (pp.255-280). Cambridge, MA: MIT Press.

Gallucci, N.T., Middleton, G., \& Kline, A. (2000). Perfectionism and creative strivings. Journal of Creative Behaviour, 34(2), 135-141.

Gardner, H. (1994). The creators' patterns. In M.A. Boden (Ed.), Dimensions of creativity (pp.75-117). Cambridge, MA: MIT Press.

Gilhooly, K.J., \& Murphy, P. (2005). Differentiating insight from non-insight problems. Thinking \& Reasoning, 11(3), 279-302. 
Goldinger, S.D., Kleider, H.M., Azuma, T., \& Bleike, D.R. (2003). "Blaming the victim" under memory load. Psychological Science, 14(1), 81-85.

Gruber, H.E., \& Wallace, D.B. (1999). The case study method and evolving systems approach for understanding unique creative people at work. In R.J. Sternberg (Ed.), Handbook of creativity (pp.93-115). Cambridge, UK: Cambridge University Press.

Guignard J., \& Lubart, T. (2006). Is it reasonable to be creative? In J.C. Kaufman \& J. Baer (Eds.) Creativity and reason in cognitive development (pp. 269-281). Cambridge, UK: Cambridge University Press.

Guilford, J.P. (1956). The structure of intellect. Psychological Bulletin, 53(4), 267293.

Johnson-Laird, P.J. (1988). Freedom and constraint in creativity. In R.J. Sternberg (Ed.), The nature of creativity (pp. 202-219). Cambridge, UK: Cambridge University Press.

Khandwalla, P.N. (1993). An exploratory investigation of divergent thinking through protocol analysis. Creativity Research Journal, 6(3), 241-259.

Khatena, J., \& Torrance, E.P. (1976). Khatena-Torrance creative perception inventory. Bensenville, IL: Scholastic Testing Service.

Klaczynski, P.A. (2000). Motivated scientific reasoning biases, epistemological beliefs, and theory polarization: A two-process account to adolescent cognition. Child Development, 71(5), 1347-1366.

McNamara, P. (2000). Counterfactual thought in dreams. Dreaming, 10(4), 237-246.

McNamara, P., Andresen, J., Arrowood, J., \& Messer, G. (2002). Counterfactual cognitive operations in dreams. Dreaming, 12(3), 121-133. 
Markman, K.D., Lindberg, M.J., Kray, L.J., \& Galinsky A.D. (2007). Implications of counterfactual structure for creative generation and analytical problem-solving. Personality and Social Psychology Bulletin, 33(3), 312-324.

Mednick, S.A. (1962). The associative basis of the creative process. Journal of Abnormal and Social Psychology, 69, 84-88.

Nickerson, R.S. (1999). Enhancing creativity. In R.J. Sternberg (Ed.), Handbook of creativity (pp. 392-430). Cambridge, UK: Cambridge University Press.

Ochse, R. (1990). Before the gates of excellence, Cambridge, UK: Cambridge University Press.

Paletz, S.B.F., \& Peng, K. (2009). Problem finding and contradiction: Examining the relationship between naïve dialectical thinking, ethnicity, and creativity. Creativity Research Journal, 21 (2 \& 3), 139-151.

Penney, C.G., Godsell, A., Scott, A., \& Balsom, R. (2004). Problem variables that promote incubation effects. Journal of Creative Behaviour, 38(1), 35-55.

Policastro, E. (1999). Intuition. In M.A. Runco \& S. Pritzker (Eds.), The encyclopaedia of creativity (Volume 2) (pp. 89-93). San Diego, CA: Academic Press.

Reiter-Palmon, R., Mumford, M.D., O’Connor Boes, J., \& Runco, M.A. (1997). Problem construction and creativity: The role of ability, cue consistency and active processing. Creativity Research Journal, 10(1), 9-23.

Reiter-Palmon, R., \& Robinson, E.J. (2009). Problem identification and construction: What do we know, what is the future? Psychology of Aesthetics, Creativity and the Arts, 3(1), 43-47. 
Rostan, S.M. (1994). Problem finding, problem-solving, and cognitive controls: An empirical investigation of critically acclaimed productivity. Creativity Research Journal, 7(2), 97-110.

Rothenberg, A. (1990). Creativity and madness. Baltimore: The John Hopkins University Press.

Runco, M.A. (2006). Reasoning and personal creativity. In J.C. Kaufman \& J. Baer (Eds.) Creativity and reason in cognitive development (pp. 99-116). Cambridge, UK: Cambridge University Press.

Runco, M.A., \& Sakamoto, S.O. (1999). Experimental studies of creativity. In R.J. Sternberg (Ed.), Handbook of creativity (pp. 62-92). Cambridge, UK: Cambridge University Press.

Ruscio, A.M., \& Amabile, T.M. (1999). Effect of instructional style on problemsolving creativity. Creativity Research Journal, 12(4), 251-266.

Sawyer, R.K. (2006). Explaining creativity: The science of human innovation, Oxford, UK: Oxford University Press.

Schooler, J.W., Ohlsson, S., \& Brooks, K. (1993). Thoughts beyond words: When language overshadows insight. Journal of Experimental Psychology: General, 122, 166-183.

Scott, T.E. (1997). The role of domain-specific knowledge in divergent thinking. Dissertation Abstracts International: Section B: The Sciences and Engineering. 57(11-B), 7256.

Segal, E. (2004). Incubation in insight problem-solving. Creativity Research Journal, 16(1), 141-148.

Simonton, D.K. (1988). Creativity, leadership and chance. In R.J. Sternberg (Ed.) The nature of creativity (pp. 386-426). Cambridge, UK: Cambridge University Press. 
Simonton, D.K. (1995). Foresight in insight? A Darwinian answer. In R.J. Sternberg \& J.E. Davidson (Eds.), The nature of insight (pp. 465-494). Cambridge, MA: MIT Press.

Sio, U.N., \& Ormerod, T.C. (2009). Does incubation enhance problem solving? A meta-analytic review. Psychological Bulletin, 135(1), 94-120.

Sio, U.N., \& Rudowicz, E. (2007). The role of an incubation period in creative problem-solving. Creativity Research Journal, 19(2-3), 307-318.

Sloman, S.A. (1996). The empirical case for two systems of reasoning. Psychological Bulletin, 119(1), 3-22.

Sloman, S.A. (2002). Two systems of reasoning. In T. Gilovich, D. Griffin \& D. Kahneman (Eds.), Heuristics and biases (pp.379-396). Cambridge, UK: Cambridge University Press.

Smith, E.R., \& DeCoster, J. (2000). Dual-process models in social and cognitive psychology: Conceptual integration and links to underlying memory systems. Personality and Social Psychology Review, 4(2), 108-131.

Smith, S.M. (1995). Getting into and out of mental ruts: A theory of fixation, incubation and insight. In R.J. Sternberg \& J.E. Davidson (Eds.), The nature of insight (pp. 65-124). Cambridge, MA: MIT Press.

Smith S.M., \& Dodds, R.A. (1999). Incubation. In M.A. Runco \& S. Pritzker (Eds.), The encyclopaedia of creativity (Volume 2) (pp. 39-43). San Diego, CA: Academic Press.

Stanovich, K.E. (1999). Who is rational?: Studies of individual differences in Reasoning. Manwah, NJ: Lawrence Erlbaum.

Stanovich, K.E. (2009). Distinguishing the reflective, algorithmic, and autonomous minds: Is it time for a tri-process theory? In J.St.B.T. Evans \& K. Frankish (Eds.), 
In two minds: Dual processes and beyond (p. 55-88). Oxford, UK: Oxford University Press.

Stanovich, K.E., \& West, R.F. (1998). Individual differences in rational thought. Journal of Experimental Psychology: General, 127(2), 161-188.

Sternberg, R.J. (2006). Cognitive psychology (4 ${ }^{\text {th }}$ Edition). Belmont, CA: Wadsworth.

Stokes, D.R. (2007). Incubated cognition and creativity. Journal of Consciousness Studies, 14(3), 83-100.

Tversky, A., \& Kahneman, D. (1983). Extensional versus intuitive reasoning: The conjunction fallacy in probability judgment. Psychological Review, 90(4), 293-315.

VanLehn, K. (1989). Problem-solving and cognitive skill acquisition. In M.I. Posner (Ed.) Foundations of cognitive science (pp. 527-579). Cambridge, MA: MIT Press.

Van Someren, M.W., Barnard, Y.F., \& Sandberg, J.A.C. (1994). Think-Aloud Method: A Practical Guide to Modelling Cognitive Processes. London: Academic Press.

Weisberg, R.W. (2006). Expertise and reason in creative thinking. In J.C. Kaufman \& J. Baer (Eds.) Creativity and reason in cognitive development (pp. 7-42). Cambridge, UK: Cambridge University Press.

Wu, P., \& Chiou, B. (2008). Postformal thinking and creativity among young adolescents: A post-Piagetian approach. Adolescence, 43(170), 237-251.

Table 1: Potential roles of type 1 and type 2 thinking during different stages of creative thinking

\begin{tabular}{|l|l|l|}
\hline Stage & Type 1 thinking & Type 2 thinking \\
\hline Problem conceptualisation & Dialectical thinking & Dialectical thinking \\
\hline
\end{tabular}




\begin{tabular}{|l|l|l|}
\hline & Counterfactual thoughts & Counterfactual reasoning \\
"'Auditing”
\end{tabular}

